\begin{tabular}{|l|l|}
\hline Postprint Version & 1.0 \\
\hline Journal website & $\underline{\text { http://www3.interscience.wiley.com }}$ \\
\hline Pubmed link & $\begin{array}{l}\text { http://www.ncbi.nlm.nih.gov/entrez/query.fcgi?db=pubmed\&cmd=Retrieve\&dop } \\
\text { t=AbstractPlus\&list_uids=16791852\&itool=iconabstr\&query_hl=15\&itool=pub } \\
\text { med_docsum }\end{array}$ \\
\hline DOI & $\underline{ }$
\end{tabular}

\title{
Time Trends in the Incidence of Eating Disorders: A Primary Care Study in the Netherlands
}

\author{
GABriËLle E. VAN SON, MA ${ }^{1 *}$ DAPHNE VAN HOEKEN, PHD ${ }^{2}$ AAD I. M. BARTELDS, MD ${ }^{3}$ ERIC F. VAN \\ FURTH, PHD ${ }^{1}$ HANS W. HOEK, MD, PHD ${ }^{2,4,5}$
}

Supported by Dutch Ministry of Health.

${ }^{1}$ Center for Eating Disorders, Ursula, Leidschendam, The Netherlands

${ }^{2}$ Parnassia, Psychiatric Institute, The Hague, The Netherlands

${ }^{3}$ NIVEL, The Netherlands Institute for Health Services Research, Utrecht, The Netherlands

${ }^{4}$ Department of Psychiatry, Groningen University, Groningen, The Netherlands

${ }^{5}$ Department of Epidemiology, Columbia University, New York, New York

* Correspondence to: G. E. van Son, Center for Eating Disorders, Ursula, PO Box: 422, 2260 AK Leidschendam, The Netherlands. E-mail: g.vanson@centrumeetstoornissen.nl

\begin{abstract}
Objective: This Dutch epidemiological study used primary care-based data to examine changes in the incidence of eating disorders in the 1990s compared to the 1980s.

Method: A nationwide network of general practitioners, serving a representative sample of the total Dutch population, recorded newly diagnosed patients with anorexia nervosa (AN) and bulimia nervosa (BN) in their practices during 1985-1989 and 1995-1999.

Results: The overall incidence of AN was stable (from 7.4 to 7.7 per 100,000). However, the incidence among 15-19- year-old females increased significantly (from 56.4 to 109.2 per 100,000). The incidence rate of $\mathrm{BN}$ decreased nonsignificantly from 8.6 to 6.1 per 100,000 .
\end{abstract}

Conclusion: The time trend of an increasing AN incidence among the high risk group continued to the end of the past century. The BN incidence did not rise as was expected.

\section{INTRODUCTION}

Information on time trends in the incidence rate of a disorder could yield clues to its etiology.

However, there have been relatively few time trend studies regarding the incidence of eating disorders. The inevitable use of health care registries in the study of the incidence of eating disorders raises a number of methodological problems: changes in admission practices and differences in referral and diagnostic procedures can bias the results and therefore hamper the interpretation. Previous studies indicate that the recorded incidence of anorexia nervosa (AN) increased until the 1970s, whereupon it seems to have stabilized. ${ }^{1}$ Two studies included in the 1990 s showed an overall stabilization. ${ }^{2,3}$ However, some studies demonstrated an increase ${ }^{4}$ or increase in a specific age group (15-24-yearolds). ${ }^{5}$ In our previous primary care-based study ${ }^{6}$ reporting on the incidence of AN between 1985 and 1989 , we did not find an increase, thus we hypothesized that the incidence of AN stabilized throughout the 1990s.

There is even less information on time trends regarding the incidence of bulimia nervosa (BN), since the disorder was only defined as a distinct diagnostic category in 1980. The three BN incidence studies conducted in the 1980s showed increases in the incidence rates, ${ }^{6-8}$ which was confirmed in a metaanalysis. ${ }^{9}$ Therefore, at the start of the data collection, we hypothesized that the incidence of BN would 
continue to increase during the 1990s. With the present primary care-based study, we aimed to investigate the hypothesized changes in the incidence of $\mathrm{AN}$ and $\mathrm{BN}$ in the 1990s compared to the 1980s.

\section{METHOD}

In the Netherlands, the Continuous Morbidity Registration Sentinel Stations (a network of general practitioners, managed by NIVEL, the Netherlands Institute for Health Services Research) ${ }^{10}$ records the number of new cases of a predetermined set of illnesses. During two periods, 1985-1989 (P1) and 1995-1999 (P2), this nationwide network of, on average (calculated over the two periods), 63 general practitioners registered the number of eating disorder patients in their practices. Every year the participating general practitioners received detailed information on eating disorders by means of a circular and at an annual meeting. Of the general practitioners who participated in $1985,53 \%(N=31)$ participated for the full term of both study periods.

General practitioners in the Netherlands play a central role in the health care system and function as the "gatekeepers" to specialized care. Even if an individual contacts a specialist directly, the general practitioner is always notified because health care insurers do not compensate for specialized health care costs without a written referral from the general practitioner. Health insurance is virtually universal in the Netherlands: between 1990 and 1999, 98\% of the total Dutch population had health insurance. ${ }^{11}$

\section{Sample}

During P1 (1985-1989), the participating general practitioners together had an average annual patient load of 148,326 people $(\approx 1 \%$ of the average Dutch population during that period). The $\mathrm{P} 1$ sample is extensively described elsewhere. ${ }^{6}$ During P2 (1995-1999), the annual average patient load was 149,797 people (again, $\approx 1 \%$ of the average Dutch population during that period). Both populations under study were representative of the total Dutch population. ${ }^{10,12}$

With the use of case identification criteria, based on DSM-III-R criteria and described in the appendix of the former report, ${ }^{6}$ the participating general practitioners considered whether each patient who consulted them might be suffering from AN or BN. Sometimes other health care workers or worried relatives alerted the general practitioner to the possibility of an eating disorder in one of their patients. To insure consistency, the same case identification criteria were used in both study periods and the same information on eating disorders was provided to the general practitioners. For each possible eating disorder patient, the general practitioner filled out an information sheet regarding eating disorder symptoms, height, weight, co-morbidity, and referrals to specialized health care. The date of first diagnosis was also noted. The research team made the DSM-IV diagnosis on the basis of the information provided by the general practitioners. If necessary, the general practitioner was asked to provide additional information. During both study periods, the same psychiatrist (author HWH) was responsible for making the final diagnoses.

After both study periods, we conducted follow-up studies that started in 1991 and 2001. The data collected via a questionnaire filled out by the general practitioner and, if available, via discharge letters from the medical specialist in attendance were used to validate the initial diagnosis. Response rates for P1 and P2 were 65 and 60\% respectively. By using the follow-up data and DSM-IV criteria for both periods, the incidence rates on the 1985-1989 data presented in this paper differed slightly from our previous report. ${ }^{6}$

During 1985-1989, the general practitioners reported a total of 178 possible new eating disorder cases. Of those, 40 cases were excluded by the research team because evidence was not conclusive, see also previous report. ${ }^{6}$ After evaluating the follow-up data, 6 additional cases ( 5 patients diagnosed with $\mathrm{AN}$ and 1 patient with $\mathrm{BN}$ ) were excluded from the sample because these cases were prevalent. Because of the change to DSM-IV criteria, we also excluded 13 cases of BN from P1: 7 patients with BN were excluded because information on the frequency of binge eating lacked, 2 patients were excluded because the criterion of binge eating twice a week was not met, and another 4 cases were excluded because they did not meet the three months duration criterion for binge eating. During 19951999, the general practitioners reported a total of 131 possible new cases of an eating disorder. Of these, 23 patients were excluded from the study because the research team concluded that they did not have an eating disorder. After evaluation of the follow-up data another 4 cases were excluded: one 
patient initially diagnosed with AN was excluded because in retrospect the general practitioner judged it was no case of an eating disorder, another patient diagnosed with AN proved to be a prevalent case and two patients with $\mathrm{BN}$ were excluded because these patients did not compensate their binges.

\section{Statistical Analysis}

The incidence rate was calculated by dividing the number of newly detected cases by 100,000 person-years of the population under study. The year of incidence was based on the time when the eating disorder was detected, because it was not possible to determine the precise date of the onset of the disorder. 95\% Confidence intervals (CI) were based on the Poisson distribution. ${ }^{13}$ Incidence rate ratios (IRRs) were calculated with STATA ${ }^{14}$ to determine if a change in incidence was statistically significant. If the $95 \%$ CI included 1 , the results were considered to be statistically non-significant. Independent samples $t$-tests with a $\alpha \leq 0.05$, two-tailed significance level were used to compare continuous variables (age and body mass index) between the two time periods. If the variable was not distributed normally, the non-parametric Mann- Whitney $U$ test was used.

\section{RESULTS}

\section{Change in Incidence}

During 1995-1999, 58 patients were first diagnosed with AN. This yielded an overall age and sex adjusted incidence rate of 7.7 per 100,000 person-years $(95 \% \mathrm{CI}=5.9-10.0)$ per year. During $1985-$ 1989 the incidence rate was 7.4 per 100,000 person-years $(95 \% \mathrm{CI}=5.6-9.7)$. The incidence rate thus remained stable over time $(\mathrm{IRR}=1.0,95 \% \mathrm{CI}=0.7-1.5)$. A total of 46 patients were first diagnosed with $\mathrm{BN}$ at $\mathrm{P} 2$. This yielded an incidence of 6.1 per 100,000 person-years $(95 \% \mathrm{CI}=4.5-8.2)$.

Compared to $1985-1989$, when the incidence was 8.6 per 100,000 person-years $(95 \% \mathrm{CI}=6.7-11.0)$, this is at a statistically non-significant decrease of $29 \%(\mathrm{IRR}=0.7,95 \% \mathrm{CI}=0.5-1.0)$.

\section{Anorexia Nervosa}

Only one male patient (2\%), aged 17 years, was detected during 1995-1999. Table 1 shows the female age-specific incidence rates of AN in both study periods. The incidence rate among 15-19year-old females increased significantly from $56.4(95 \% \mathrm{CI}=32.8-90.3)$ to $109.2(95 \% \mathrm{CI}=70.0$ 162.6) per 100,000 female-years during $\mathrm{P} 2(\mathrm{IRR}=1.9,95 \% \mathrm{CI}=1.1-3.6)$, an increase of $94 \%$. In both study periods, the age-specific incidence was highest in the 15-19 year age group. There were no other significant changes in the age-specific incidence rates. The mean age of the cases with AN in the second study period did not differ from the first study period ( $\mathrm{P} 1$ : mean age $=22.8 \pm \mathrm{SD}=8.3$, median $=21 ; \mathrm{P} 2$ : mean age $=21.9 \pm \mathrm{SD}=7.9$, median $=19)$, nor did the mean body mass index $(\mathrm{BMI})(\mathrm{P} 1$ : mean $\mathrm{BMI}=16.3 \pm \mathrm{SD}=1.5$, median $=16 ; \mathrm{P} 2$ : mean $\mathrm{BMI}=16.6 \pm \mathrm{SD}=1.7$, median $=17)$.

\section{[ TABLE 1$]$}

\section{Bulimia Nervosa}

A comparison of the age-specific incidence of BN for females in both periods is shown in Table 2. We found one male patient (2\%), aged 34 years. In P1 the highest age-specific incidence, 59.9 (95\% $\mathrm{CI}=36.1-93.6)$ per 100,000 female-years, was in the 25-29 year age group. In P2 the age-specific incidence was highest in the 15-19 and 20-24 age groups (respectively, 41.0 and 42.6 per 100,000 female-years). None of the age-specific incidence rate ratios reached statistical significance. The mean age in the second study period did not differ from the first study period $(\mathrm{P} 1$ : mean age $=27.3 \pm \mathrm{SD}=$ 8.7 , median $=25 ; \mathrm{P} 2$ : mean age $=27.0 \pm \mathrm{SD}=7.6$, median $=25$ ). The mean BMI was significantly higher in the first study period than in the second $(\mathrm{P} 1$ : mean $\mathrm{BMI}=30.2 \pm \mathrm{SD}=7.7$, median $=30 ; \mathrm{P} 2$ : mean $\mathrm{BMI}=25.1 \pm \mathrm{SD}=6.6$, median $=23$; Mann-Whitney $U$ test $=587, p=.001$ ). To examine this further, we divided the cases into age categories (10-19 years, 20-29 and 30 years and older). The mean BMI had decreased in all age categories but only dropped significantly among the 20-29-yearold females $(t=4.3 ; \mathrm{df}=44, p<.0001)$. 


\section{[ TABLE 2 ]}

\section{CONCLUSION}

This nationwide primary care-based study assessed changes in the incidence of eating disorders in the Netherlands by comparing two five-year periods a decade apart (in the 1980s and the 1990s). The overall incidence of AN remained constant, a finding which confirmed our hypothesis. However, the incidence among the 15-19-year-old females increased significantly. Contrary to our hypothesis, the incidence rate of BN did not continue to rise into the $1990 \mathrm{~s}$, but showed a statistically non-significant decreasing trend.

Previously Lucas et al. ${ }^{15}$ have found that the incidence of AN increased in the high risk group of young females during the past century till the end of the eighties. Our findings indicate that this time trend of an increasing incidence of AN among the high risk group continued to the end of the past century. The incidence rate for late-onset AN remained low. On the one side, the increase among the female 15-19-year-olds might be explained by improved diagnostic skills of the general practitioners. Since the 1990s eating disorders have become standard in the curriculum of medical students and general practitioner training. Also a learning curve in recognizing eating disorder symptoms of the participating general practitioners cannot be excluded. On the other side, there was growing public awareness of eating disorders through increased media attention during the 1990s. ${ }^{16}$ This might have facilitated early recognition of symptoms by patients and by parents, which might have led to seeking professional help at an earlier stage of the disorder. Together these developments might have resulted in patients with an eating disorder being diagnosed at an earlier stage of the disorder compared to the first study period. This would mean a positive development in the early recognition of eating disorders.

Another explanation for the increase in the 15-19-year-old females might be that patients are developing AN at an earlier age compared to the first study period. On the basis of our data, which use date of detection, not necessarily close to age of onset, this possibility cannot be ruled in or out.

The incidence rate of BN in our study did not continue to rise into the 1990s. A recent British report shows a decline in the incidence rate of BN in UK primary health care. ${ }^{3}$ And in a prevalence study among US female college students it was found that the point prevalence of $\mathrm{BN}$ decreased when comparing assessments in 1982, 1992, and 2002. ${ }^{17}$ In our study, the incidence rate of BN in the second study period was lower compared to AN. This is in contrast to evidence from other epidemiologic studies. ${ }^{1}$

The high risk group of BN in our study shifted from 25-29 to 15-24-year-old females. Simultaneously, the mean BMI of the BN group dropped significantly. The typical patient with BN in the 1990s seems to be younger with a lower BMI compared to the 1980s. Possibly, bulimic behaviors were popular as dieting methods during the 1980s among overweight women in their late twenties. In 1981 a survey of college students revealed that individuals with bulimia symptoms had a history of overweight or tended to be in the upper portion of their normal weight range. ${ }^{18}$ Moreover, vomiting as a weight controlling behavior was found in subjects within the normal range of psychological functioning. The frequency did not distinguish them from patients with BN. ${ }^{19}$

The trend of an increasing mean BMI of the total population might also play a role. The BMI of the population is rising in adults ${ }^{20}$ as well as in children and adolescents ${ }^{21}$ However, this does not lead towards an increase in the incidence of BN. This may relate to the adolescents' frame of reference: the majority of adolescents compare themselves to peers rather than to "ideal" models. ${ }^{22}$ Thus, when being overweight becomes more common, the reference for self-evaluation shifts upward and one is less likely to perceive oneself as being overweight. This might have a relaxing effect on the need to control weight aggressively.

\section{Strengths and Limitations}

By using a primary care-based design, the first filter of health care, ${ }^{23}$ we avoided several methodological pitfalls common to studies that depend solely on psychiatric or hospital records. We also met the methodological criteria for studying incidence rate changes. ${ }^{4}$ Thus, changes in referral or admission practices had no influence on our study results, because the general practitioners also provided information on subjects that were not referred or admitted to psychiatric or hospital care. The application of the same case finding and diagnostic methods during the two periods was another 
Son, G.E. van, Hoeken, D. van, Bartelds, A.I., Furth, E.F. van, Hoek, H.W.

Time trends in the incidence of eating disorders: a primary care study in The Netherlands.

International Journal of Eating Disorders: 39, 2006, nr. 7, p. 565-569

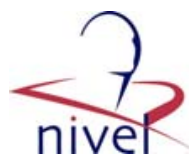

strength of the study. The same case identification criteria were used, the same information on eating disorders was provided to the general practitioners, in both periods, DSM-IV criteria were applied, and the same author made the final diagnosis. Furthermore, we were able to increase the reliability of the diagnosis by using follow-up data.

A limitation of the study is that we cannot be sure whether all patients with an eating disorder consult their general practitioner. However, the chance of bias that stems from patients seeking alternative health care instead of regular health care, which would render them invisible in our study, is considered low. In the Netherlands, primary care, but not alternative medicine, is covered by insurance and is therefore free of cost to the patient. It is also easily accessible and widely accepted as the first level of care. Another limitation, as in all other incidence studies on eating disorders, is that there are always patients who remain unrecognized as an eating disorder patient, leading to an underestimation of the true incidence. Eating disorders are known to be difficult to detect in primary care and other health care settings. ${ }^{24-26}$ However, in our study the general practitioners received training to enhance their diagnostic skills and focused specifically on recognizing eating disorders. With respect to bias caused by improved case recognition, it is likely that a learning curve for recognizing eating disorders occurred. First, more than half of the general practitioners who participated during the first year participated in both study periods, and so they can be expected to have become more sensitive to recognizing eating disorder symptoms. Second, eating disorders have become a standard in the curriculum of medical students and general practitioner training since the 1990s. However, a strong bias of this kind would also imply that we should see increases in incidence within and between study periods, and this is not the case. Finally, the age of onset of the eating disorders was unknown. We were only aware of age of detection.

We conclude that the time trend of an increasing AN incidence among the high risk group (15-19year-old females) has continued to the end of the past century. The BN incidence did not rise as was expected.

The authors thank the participating general practitioners for their efforts collecting the data, and Alexandra Dingemans for her comments on the manuscript.

\section{TABLES}

TABLE 1. Age-specific incidence rates of anorexia nervosa per year per 100,000 females in primary care in the Netherlands, 1985-1989 and 1995-1999

\begin{tabular}{|c|c|c|c|c|c|c|c|c|}
\hline \multirow[b]{2}{*}{ Age } & \multicolumn{4}{|c|}{ 1985-1989 } & \multicolumn{4}{|c|}{ 1995-1999 } \\
\hline & $N$ & Incidence Rate & $95 \% \mathrm{Cl}$ & Female-Years & $N$ & Incidence Rate & $95 \% \mathrm{Cl}$ & Female-Years \\
\hline $5-9$ & - & - & - & - & 1 & 4.5 & $0.0-25.1$ & 22,230 \\
\hline $10-14$ & 2 & 8.6 & $1.0-31.1$ & 23,245 & 4 & 18.4 & $5.0-47.0$ & 21,776 \\
\hline 15-19 & 17 & 56.4 & $32.8-90.3$ & 30,155 & 24 & 109.2 & $70.0-162.6$ & 21,969 \\
\hline $20-24$ & 13 & 39.5 & $21.0-67.6$ & 32,900 & 9 & 32.0 & $14.6-60.7$ & 28,164 \\
\hline $25-29$ & 13 & 41.0 & $21.8-70.1$ & 31,700 & 10 & 30.0 & $14.4-55.1$ & 33,376 \\
\hline 30-34 & 2 & 6.8 & $0.8-24.7$ & 29,300 & 1 & 3.2 & $0.1-17.6$ & 31,643 \\
\hline $35-64$ & 3 & 2.3 & $0.5-6.6$ & 133,055 & 8 & 5.6 & $2.4-11.1$ & 141,895 \\
\hline $10-64$ & 50 & 17.8 & $13.2-23.5$ & 280,355 & 56 & 20.1 & $15.2-26.1$ & 278,823 \\
\hline All ages & 50 & 13.4 & 9.9-17.6 & 373,975 & 57 & 15.0 & $11.4-19.4$ & 379,880 \\
\hline
\end{tabular}

TABLE 2. Age-specific incidence rates of bulimia nervosa per year per 100,000 females in primary care in the Netherlands, 1985-1989 and 1995-1999

\begin{tabular}{|c|c|c|c|c|c|c|c|c|}
\hline \multirow[b]{2}{*}{ Age } & \multicolumn{4}{|c|}{ 1985-1989 } & \multicolumn{4}{|c|}{ 1995-1999 } \\
\hline & $N$ & Incidence Rate & $95 \% \mathrm{Cl}$ & Female-Years & $N$ & Incidence Rate & $95 \% \mathrm{Cl}$ & Female-Years \\
\hline $10-14$ & 1 & 4.3 & $0.1-24.0$ & 23,245 & - & - & - & - \\
\hline 15-19 & 9 & 29.8 & $13.7-56.7$ & 30,155 & 9 & 41.0 & $18.7-77.8$ & 21,969 \\
\hline $20-24$ & 15 & 45.6 & $25.5-75.2$ & 32,900 & 12 & 42.6 & $22.0-74.4$ & 28,164 \\
\hline 25-29 & 19 & 59.9 & $36.1-93.6$ & 31,700 & 10 & 30.0 & $14.4-55.1$ & 33,376 \\
\hline $30-34$ & 4 & 13.7 & $3.7-35.0$ & 29,300 & 5 & 15.8 & $5.1-36.9$ & 31,643 \\
\hline $35-64$ & 14 & 10.5 & $5.8-17.7$ & 133,055 & 9 & 6.3 & $2.9-12.0$ & 141,895 \\
\hline $10-64$ & 62 & 22.1 & $17.0-28.4$ & 280,355 & 45 & 16.1 & $11.8-21.6$ & 278,823 \\
\hline All ages & 62 & 16.6 & $12.7-21.3$ & 373,975 & 45 & 11.8 & $8.6-15.9$ & 379,880 \\
\hline
\end{tabular}


Son, G.E. van, Hoeken, D. van, Bartelds, A.I., Furth, E.F. van, Hoek, H.W.

Time trends in the incidence of eating disorders: a primary care study in The Netherlands.

International Journal of Eating Disorders: 39, 2006, nr. 7, p. 565-569

\section{REFERENCES}

1. Hoek HW, Van Hoeken D. Review of the prevalence and incidence of eating disorders. Int J Eat Disord 2003;34: 383-396.

2. Milos G, Spindler A, Schnyder U, Martz J, Hoek HW, Willi J. Incidence of severe anorexia nervosa in Switzerland: 40 years development. Int J Eat Disord 2004;35:250-258.

3. Currin L, Schmidt $\mathrm{U}$, Treasure J, Jick $\mathrm{H}$. Time trends in eating disorder incidence. $\mathrm{Br} \mathrm{J}$ Psychiatry 2005;186:132-135.

4. Eagles JM, Johnston MI, Hunter D, Lobban M, Millar HR. Increasing incidence of anorexia nervosa in the female population of northeast Scotland. Am J Psychiatry 1995;152:12661271.

5. Lucas AR, Crowson CS, O'Fallon MW, Melton LJ. The ups and downs of anorexia nervosa. Int J Eat Disord 1999;26:397-405.

6. Hoek HW, Bartelds AIM, Bosveld JJF, Graaf Yvd, Limpens VEL, Maiwald M, et al. Impact of urbanization on detection rates of eating disorders. Am J Psychiatry 1995;152:1272-1278.

7. Soundy TJ, Lucas AR, Suman VJ, Melton LJ. Bulimia nervosa in Rochester, Minnesota from 1980 to 1990. Psychol Med 1995; 25:1065-1071.

8. Turnbull S, Ward A, Treasure J, Jick H, Derby L. The demand for eating disorder care: An epidemiological study using the general practice research database. Br J Psychiatry 1996;169:705-712.

9. Keel PK, Klump KL. Are eating disorders culture-bound syndromes? Implications for conceptualizing their etiology. Psychol Bull 2003;129:747-769.

10. Bartelds AIM. Continuous Morbidity Registration Sentinel Stations The Netherlands 1998. Utrecht: Nivel, 2000.

11. Health Care Information Centre. Health care: Dutch insurance industry in figures, 2003. The Hague: Dutch Association of Insurers, 2004, pp. 124-132.

12. Bartelds AIM. Continuous Morbidity Registration Sentinel Stations The Netherlands 1995. Utrecht: Nivel, 1996.

13. Frome EL, Checkoway $\mathrm{H}$. Use of Poisson regression models in estimating incidence rates and ratios. Am J Epidemiol 1985; 121:309-323.

14. StataCorp. Stata Statistical Software: Release 9. StatCorp LP: College Station, TX, 2005.

15. Lucas AR, Beard MC, O'Fallon MW, Kurland LT. 50-year trends in the incidence of anorexia nervosa in Rochester, Minnesota: A population-based study. Am J Psychiatry 1991;148:917922.

16. Schoemaker C. Anorexia now exists: A follow-up study on the coverage of anorexia nervosa in the Volkskrant. Maandblad Geestelijke volksgezondheid 2004;59:831-838.

17. Keel PK, Heatherton TF, Dorer DJ, Joiner TE, Zalta AK. Point prevalence of bulimia nervosa in 1982, 1992, and 2002. Psychol Med 2006;36:119-127.

18. Halmi KA, Falk JR, Schwartz E. Binge-eating and vomiting: A survey of a college population. Psychol Med 1981;11:697-706.

19. Olmsted MP, Garner DM. The significance of self-induced vomiting as a weight control method among nonclinical samples. Int J Eat Disord 1986;5:683-700.

20. Visscher TLS, Kromhout D, Seidell J. Long-term and recent time trends in the prevalence of obesity among Dutch men and women. Int J Obes 2002;26:1218-1224.

21. Fredriks AM, Van Buuren S, Verloove-Vanhorick PS. Body index measurements in 1996-97 compared with 1980. Arch Dis Child 2000;82:107-112.

22. Kaltiana-Heino R, Kautiainen S, Virtanen SM, Rimpela A, Rimpela M. Has adolescents' weight concern increased over 20 years? Eur J Public Health 2003;13:4-10.

23. Goldberg D, Huxley P. Mental Illness in the Community: The Pathway to Psychiatric Care. London: Tavistock, 1980.

24. Whitehouse AM, Cooper PJ, Vize CV, Hill C, Vogel L. Prevalence of eating disorders in three Cambridge general practices: Hidden and conspicuous morbidity. Br J Gen Pract 1992;42:5760.

25. Johnson JG, Spitzer RL, Williams JBW. Health problems, impairment and illnesses associated with bulimia nervosa and binge eating disorder among primary care and obstetric gynaecology patients. Psychol Med 2001;31:1455-1466.

26. King MB. Eating disorders in a general practice population. Prevalence, characteristics and follow-up at 12 to 18 months. Psychol Med 1989;14:1-34. 